\title{
Diagnostic characters of Juncus (Juncaceae) species in Korea
}

\author{
Sungmin Kim and Sangtae Kim* \\ Department of Biology and Basic Science Institute, Sungshin Women's University, Seoul 136-742, Korea \\ (Received 17 June 2013; Accepted 18 August 2013)
}

\section{한국산 골풀속(골풀과) 식물들의 식별 형질 \\ 김성민 · 김상태* \\ 성신여자대학교}

\begin{abstract}
As a recent infrageneric classification of Juncus (Juncaceae), Kirschner suggested two subgenera which are distinguished by the type of inflorescence and the absence/presence of bracteole along with 10 sections which are distinguished by the characters of the leaves, the position of the inflorescence, and types of stamens and seeds. However, an intensive morphological investigation on Korean Juncus has yet to be performed. We surveyed the morphological characters of 14 taxa distributed throughout the Korean peninsula, including one North Korean taxon. The quantitative and qualitative characters of rhizomes, leaves, inflorescences, flowers, fruits, and seeds were investigated on each taxon using about 950 specimens of Korean Juncus on loan from major Korean herbaria. As a result, we provide diagnostic characters with illustrations and a key to Korean Juncus.
\end{abstract}

Keywords: Juncaceae, Juncus, morphological characters, key, electron microscopy

적 요: 전 세계 Juncus (골풀속)의 속내 분류체계는 최근 Kirschner에 의해 2아속 10절로 정리된 바 있으며, 두 아속은 소포의 유무와 화서에 의해 구분되며, 각각의 절은 잎의 특징, 화서의 위치, 수술, 종자의 형질 등 에 따라 구분된다. 현재까지 한국산 Juncus 분류군들을 구분하는 형질들에 대한 종합적 검토는 미흡한 상태 이다. 그러므로 본 연구는 지금까지 한반도에 자생한다고 보고된 분류군들 중 채집 및 표본조사가 가능한 14 개의 Juncus 분류군들에 대하여 국내 11 개 표본관으로부터 약 950 점의 표본을 대여하여 조사하였고, 이들에 대한 지하경, 잎, 화서, 꽃, 과실, 종자 등의 외부형태학적 형질들에 대한 형질상태의 유형을 파악하여 도해하 고, 분류군들 간의 구분성을 검토하였다. 이를 바탕으로 주요 식별 형질들을 이용한 검색표를 제시하였다.

주요어: 골풀과, 골풀속, 형태형질, 검색표, 전자현미경

골풀속(Juncus L., 1753)이 속하는 골풀과(Juncaceae Juss., 1789)는 세계적으로는 7속 440여 종이 남극을 제외 한 전 지역, 주로 북온대의 습지와 고산 지역에 걸쳐 광범 위한 서식지를 갖는다(Cronquist, 1981; Mabberley, 1987; Balslev, 1996; Kirschner, 2002a, b). 골풀과는 수염 뿌리를 가지며 지하경이 발달하기도 하고, 줄기는 원형 또는 편 평형이며, 엽초는 닫히거나 열리며, 화피는 6 개가 3 개씩

\footnotetext{
*Author for correspondence: amborella@sungshin.ac.kr
}

http://www.pltaxa.or.kr

Copyright (C) 2013 the Korean Society of Plant Taxonomists
두 줄로 배열되어 떨어져 있고 숙존하며, 수술은 3 개 또는 6 개이며, 열매가 삭과라는 특징을 갖는다. 전통적으로 골 풀과 내에서는 골풀속, 뀡의밥속(Luzula DC.), Distichia Ness \& Meyen, Marsippospermum Desv., Oxychloe Philippi, Patosia Buchen., Rostkovia Desv., Prionium E. Meyer의 여덟 속을 인식하여 왔으나(Cronquist, 1981; Clemants, 1990; Takhtajan, 1997), 최근 $r b c L$ 유전자에 의한 연구(Munro and Linder, 1998)는 Prionium이 골풀과와 분리되는 단계통군 (monophyletic group)임을 보여주어 Prioniaceae S. L. Munro \& H. P. Linder로 승격시킴으로써 최근에는 일곱 속 만을 골 풀과에 포함시키고 있다(Kirschner, 2002a, b). 이들 일곱 속 들 중에서 골풀속의 종다양성이 가장 높으며(315종), 꿩의 
밥속이 그 다음이다(115종). 나머지 5속인 Distichia (3종), Marsippospermum (3종), Oxychloe (6종), Patosia (1종), Rostkovia (2종)는 종 다양성이 매우 낮고, 한반도에 분포하 지 않고 남반구에서만 서식한다(Cronquist, 1981; Clemants, 1990; Balslev, 1996; Kirschner, 2002a, b; Roalson, 2005).

골풀속 내의 분류군들에 대하여 Linnaeus (1753)가 최초 로 15 종을 기재하였는데, 줄기에 잎이 있는 부류와 잎이 없는 부류를 인식하였다. 이후 Buchenau (1890)는 최초로 전 세계의 골풀과를 정리하여 출판하였는데, 꽃 아래에 소포가 있는 "prophyllati"와 소포가 없는 "eprophyllati"로 나누었고 이들을 화서와 잎의 유형에 따라 8 개의 아속으 로 분류하여 종 기재와 형태 형질을 도해한 바 있다. Satake는 일본을 포함한 동아시아의 골풀속에 대하여 외 부형태적 연구와 잎의 해부학적 연구(Sadake, 1931a, b), 종 자의 표피구조 연구(Sadake,1932) 등을 통하여, 37분류군 에 대하여 5 아속, 8 절, 4 아절 20 열로 분류하였고, 이들 중 16종 2변종이 한국에 분포함을 밝혔다(Sadake,1938). Novara (1976)는 소포가 있는 종은 취산화서(cyme)를 갖고 소포가 없는 종은 총상화서(raceme)를 갖는다는 특징을 인식 하였고, Brooks and Kuhn (1986), Kardrym and Khalik (2010) 등은 종자의 형태와 크기가 종을 구별하는 형질로 유용함을 제시한 바 있다. 최근 골풀속을 포함한 골풀과 전체에 대한 분류학적 재고찰이 이루어진 바 있는데 (Kirschner 2002a, b), 여기에서 골풀속은 2아속 10절의 315 종으로 정리되어 기재된 바 있다.

골풀속에 속하는 한국산 분류군에 대해서는 Palibin (1901)이 J. compressus Jacq., J. effusus L.와 J. pauciflorus R. $\mathrm{Br}$ 를 보고한 이래 Nakai (1911; 9종), Chung et al. (1937; 6종), Satake (1938; 16종 2변종), Park (1949; 18종 2변종), Nakai (1952; 16종 4변종), Chung (1957, 1965; 13종), Lee (1989; 15 종 2변종), Lee, Y. N. (1996; 15종 2변종), Lee, W. T. (1996a, b; 16 종 2변종), Im (2000; 19종 6변종)은 각각 다르게 분류군들 을 인식하였지만, 최근 정리된 국가표준식물목록(Korea National Arboretum and the Plant Taxonomic Society of Korea, 2007)에서는 날개골풀(J. alatus Franch. \& Sav.), 참골풀(J. brachyspathus Maxim.), 애기골풀(J. bufonius L.), 별날개골풀 (J. diastrophanthus Buchen.), 골풀(J. decipiens (Buchen.) Nakai $=J$. effusus var. decipiens Buchen.), 물골풀(J. gracillimus V. I. Krecz. \& Gontsch.), 갯골풀(J. haenkei E. May.), 한라골풀(J. hallasanensis T. H. Chung), 비녀골풀(J. krameri Franch. \& Sav.), 참비녀골풀(J. prismatocarpus subsp. leschenaultii (Laharpe) Kirschner $=J$. leschenaultii J. Gay.), 실비녀골풀 $(J$. maximowiczii Buchen.), 솔비녀골풀(J. ounsanensis T. H. Chung), 청비녀골풀(J. papillosus Franch. \& Sav.), 백두실골풀 (J. potaninii Buchen.), 푸른갯골풀 $(J$. setchuensis Buchen. $=J$. setchuensis var. effusoides Buchen.), 태백비녀골풀(J. stygius L.), 길골풀 $(J$. tenuis Willd.), 설령골풀(J. triceps Rostk.), 구름 골풀 $(J$. triglumis $\mathrm{L}$.), 눈비녀골풀 $(J$. wallichianus Lahar.)의 20
분류군을 인식하고 있다. 비슷한 시기에 정리된 "The Genera of Vascular Plants of Korea" (Oh and Lee, 2007)에서는 한라골풀과 솔비녀골풀을 제외한 18 분류군을 수록하였다. Kim (2012)은 북한에 분포하는 5 종을 제외한 한국산 분류 군들을 재고찰하여 14 분류군으로 정리 하였는데, 러시아, 일본에 분포한다고 알려져 있었던 검정납작골풀(J. fauriei Lév. \& Vaniot)을 미기록종으로 포함한 바 있다. 한반도의 골 풀속 분류군들은 Kirschner (2002a, b)가 인식한 10 개의 절들 중, 청비녀골풀, 눈비녀골풀, 비녀골풀은 sect. Ozophyllum 에, 실비녀골풀, 백두실골풀, 설령골풀, 구름골풀은 sect. Stygiopsis에, 날개골풀, 별날개골풀, 참비녀골풀은 sect. Iridifolii에, 애기골풀은 sect. Tenageia에, 골풀, 푸른갯골풀, 갯골풀, 참골풀, 검정납작골풀은 sect. Juncotypus에, 길골풀, 물골풀은 sect. Steirochloa에 속한다.

본 연구에서는 채집 및 표본조사가 가능한 한반도에 분 포하는 골풀속에 속하는 14 분류군들에 대하여 표본들에 대한 조사를 실시하였다. 이들의 형태적 연구를 통하여 형 질들의 유형을 구분하고 형질상태들의 연속성을 파악하 여 분류군들 간의 구분성을 확인 하였고, 이를 바탕으로 골풀속에 속하는 분류군들에 대한 검색표를 작성하였다.

\section{재료 및 방법}

본 연구에 사용된 실험재료는 2009년부터 2012년에 자 생지에서 채집한 생체 표본들과 성신여자대학교표본관 (SWU), 서울대학교표본관(SNU), 서울대학교수우식물표 본관(SNUA), 국립수목원표본관(KH), 국립생물자원관표 본관(NIBR), 고려대학교표본관(KUS), 이화여자대학교표 본관(EWH), 성균관대학교표본관(SKK), 강원 대학교표본 관(KWNU), 아주대학교표본관(AJOU), 충북대학교표본 관(CBU)에 소장된 석엽표본들을 이용하였다. 골풀속 식 물의 종자의 모양과 표피는 주사전자현미경으로 관찰하 였다. 이를 위하여 먼저 종자 표면의 이물질 제거를 위해 생체 및 석엽 표본에서 채취한 종자를 증류수가 담긴 초 음파 세척기(NXP1002, Nexul, Korea)에서 약 20분 처리 후 자연 건조시켰고, 건조된 종자는 약 30-40 nm 두께로 백금 이온 증착 후 주사전자현미경(SEM; JSM-7500F, Jeol, Japan)을 이용하여 관찰하였다.

\section{결과 및 고찰}

식물의 생태형: 생태형은 다년생 초본과 일년생 초본으 로 나눌 수 있으며, 일년생 초본은 애기골풀이고, 나머지 분류군은 모두 다년생 초본이다.

뿌리: 뿌리는 수염뿌리를 가지며, 청비녀골풀에서는 지 하 뿌리에 별 모양의 부정아(adventitious bud)를 형성하기 도 한다(Fig. 1D).

지하경 및 포복경: 네 가지 유형의 지하경 및 포복경이 

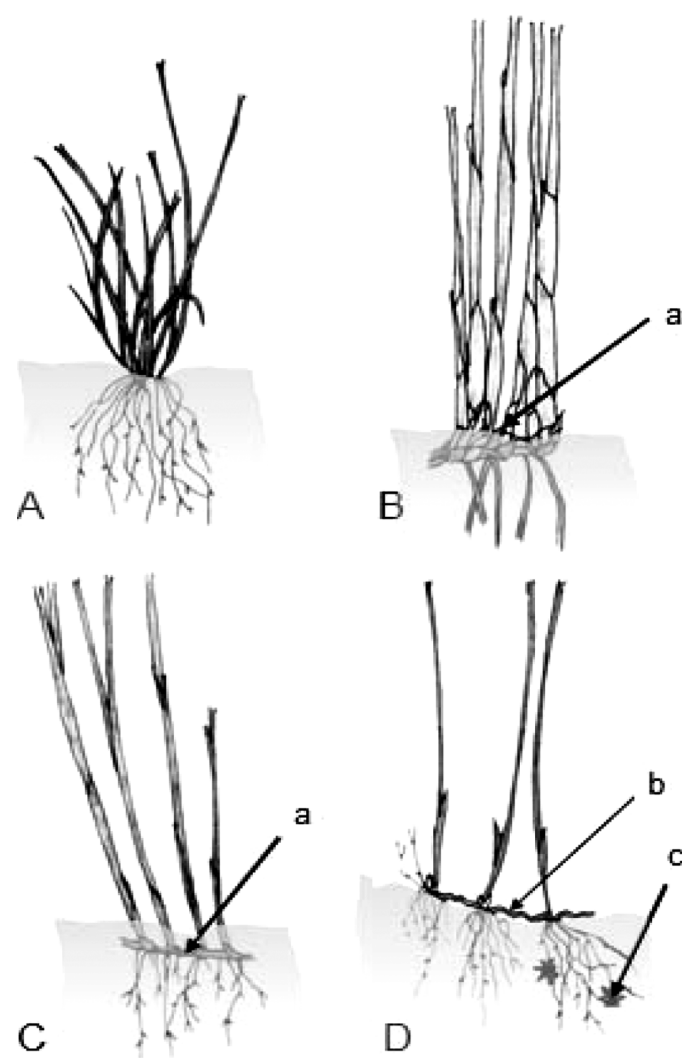

Fig. 1. Rhizome and stolon types of the Korean Juncus. A, Denselyinternoded rhizome; B, Short-internoded rhizome; C, Long-internoded rhizome; D, Stolon. a, internode; b, stolon; c, adventitious bud.

관찰된다. 애기골풀은 일년생 초본으로 지하경이 없이 총 생한다. 다년생인 나머지 분류군 중 구름골풀, 실비녀골 풀, 날개골풀, 별날개골풀, 참비녀골풀, 눈비녀골풀, 길골 풀 등은 절간이 매우 짧아 줄기가 총생하는 것으로 보이 는 밀집절간지하경형(densely-internoded rhizome type; Fig. $1 \mathrm{~A})$ 이고, 골풀, 푸른갯골풀은 지하경이 발달하여 옆으로 벋지만 마디 간격이 매우 짧은 형태인 단절간지하경형 (short-internoded rhizome type; Fig. 1B), 비녀골풀과 물골풀 은 지하경이 발달하여 옆으로 벋고 마디 간격이 길고 뚜 렷한 형태인 장절간지하경형(long-internoded type; Fig. $1 \mathrm{C})$, 청비녀골풀은 특징적으로 지상에서 포복지(stolon)가 벋는 형태인 포복지형(stolon type; Fig. 1D)이다.

줄기: 줄기의 단면은 원형(terete), 타원형(subterete), 편평 형(flat), 편평날개형(winged flat)으로 구분된다(Fig. 2). 원형 에 해당하는 분류군은 구름골풀, 실비녀골풀, 애기골풀, 길골풀, 물골풀, 골풀, 푸른갯골풀이며, 타원형에 해당하 는 분류군은 눈비녀골풀, 비녀골풀, 청비녀골풀이다. 날개 골풀, 별날개골풀, 참비녀골풀은 줄기의 단면이 납작하고 날개가 달려 있어 줄기의 폭이 다른 종들과 차이가 난다. 날개가 없는 편평형의 줄기는 최근 한반도 미기록종으로 보고된(Kim et al., 2012) 검정납작골풀에서만 발견된다.

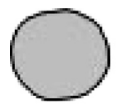

A

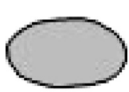

$\mathrm{B}$

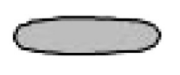

C
Fig. 2. Cross section of stem of Korean Juncus. A, Terete; B, Subterete; C, Flat; D, Winged flat.

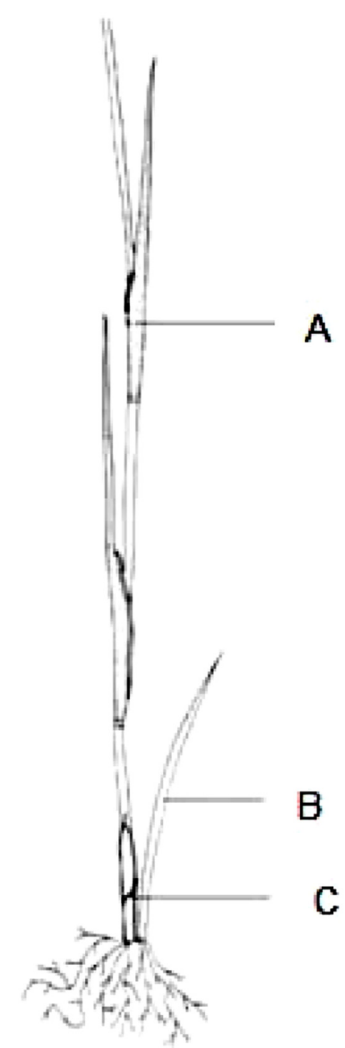

Fig. 3. Leaf terminology of the Korean Juncus. A, Cauline leaf; B, Basal leaf; C, Cataphyll.

잎: 잎은 형태와 위치에 따라 인엽(cataphyll), 근생엽 (basal leaf), 경생엽(cauline leaf)으로 나뉘는데, 이 세가지 잎을 모두 갖거나, 인엽만을 갖거나, 근생엽과 인엽만을 갖는 유형이 있다(Fig. 3, Table 1). 인엽은 줄기의 기부에 비늘모양으로 줄기를 감싸며 선단부가 급첨두로 뾰족하 며 분류군에 따라 1-4장이다. 인엽이 여러 장일 경우 각각 의 인엽의 길이는 안쪽으로 갈수록 길어진다(Fig. $3 \mathrm{C}$ ). 근 생엽이나 경생엽이 없고 인엽만을 갖는 분류군은 골풀, 푸른갯골풀과 검정납작골풀이다. 근생엽은 줄기의 기부 에서 나오는 잎으로 경생엽과 동일한 모양이며 분류군에 따라 1-4장의 근생엽을 갖는다. 경생엽은 원줄기의 마디 부위에서 나오며, 하부에 열린 모양의 엽초가 줄기를 감 싸고, 분류군에 따라 1-4장으로 나타난다. 길골풀의 경우 근생엽(1-2장)과 인엽(1장)을 갖으나 경생엽을 갖지 않아 
서 경생엽을 갖는 다른 종들과 구별된다. 경생엽과 근생 엽의 횡단면은 원형(terete), 타원형(subterete), 납작형(flat), 양가장자리가 위로 약간 말리는 내권형(involute)의 네 가 지 유형으로 구분된다(Fig. 4A, Table 1). 횡단면이 원형인 것은 구름골풀, 눈비녀골풀이고, 타원형인 것은 실비녀골 풀, 비녀골풀, 청비녀골풀, 납작형인 것은 날개골풀, 별날 개골풀, 참비녀골풀, 내권형인 것은 애기골풀, 길골풀, 물 골풀이다. 잎에 가로로 발달한 격막은 일부 절을 구분하는
데 유용한 형질이다. 완전한 격막(perfectly septate)은 sect. Ozophyllum 에 속하는 눈비녀골풀, 비녀골풀, 청비녀골풀 에서 발견되고, 불완전 격막(imperfectely septate)은 sect. Iridifolii에 속하는 날개골풀, 별날개골풀, 참비녀골풀에서 발견된다(Fig. 4B, Table 1). 경생엽과 근생엽의 정단부는 둔두(obtuse)와 예두(acute)의 두 가지 형태로 구분된다 (Fig. 4C, Table 1). 정단부가 둔두인 분류군은 구름골풀, 실 비녀골풀, 비녀골풀, 청비녀골풀이고, 예두인 것은 날개

Table 1. Qualitative morphological characters of the Korean Juncus

\begin{tabular}{|c|c|c|c|c|c|c|}
\hline $\begin{array}{ll}\text { Characters } & \text { Taxa } \\
\end{array}$ & J. triglumis & J. maximowiczii & J. alatus & J. diastrophanthus & $\begin{array}{l}\text { J. prismatocarpus } \\
\text { subsp. leschenaultii }\end{array}$ & J. wallichianus \\
\hline C1. Plant longevity & perennial & perennial & perennial & perennial & perennial & perennial \\
\hline C2. Plant caespitose & yes & yes & yes & yes & yes & yes \\
\hline C3. Rhizome/stolon & $\begin{array}{l}\text { densely- } \\
\text { internoded rhi. }\end{array}$ & $\begin{array}{l}\text { densely- } \\
\text { internoded rhi. }\end{array}$ & $\begin{array}{l}\text { densely- } \\
\text { internoded rhi. }\end{array}$ & $\begin{array}{l}\text { densely- } \\
\text { internoded rhi. }\end{array}$ & $\begin{array}{l}\text { densely- } \\
\text { internoded rhi. }\end{array}$ & $\begin{array}{l}\text { densely- } \\
\text { internoded rhi. }\end{array}$ \\
\hline C4. Cross section of stem & terete & terete & winged flat & winged flat & winged flat & subterete \\
\hline C5. Cataphyll & absent & present & present & present & present & present \\
\hline C6. Basal leaf & present & present & present & present & present & present \\
\hline C7. Cauline leaf & present & present & present & present & present & present \\
\hline C8. Cauline leaf apex & obtuse & obtuse & acute & acute & acute & acute \\
\hline C9. Auricle & present & present & present & present & present & present \\
\hline C10. Auricle shape & obtuse & obtuse & obtuse & obtuse & obtuse & obtuse \\
\hline C11. Septation of leaf blade & not septate & not septate & imperfectly & imperfectly & imperfectly & perfectly \\
\hline C12. Inflorescence type & head type raceme & raceme & raceme & raceme & raceme & raceme \\
\hline C13. Primary bract shape & _- & leaf-like & leaf-like & leaf-like & leaf-like & leaf-like \\
\hline C14. Primary bract apex & - & obtuse & acute & acute & acute & acute \\
\hline $\begin{array}{l}\text { C15. Primary bract relative } \\
\text { length }\end{array}$ & - & $\begin{array}{l}\text { shorter than } \\
\text { inflorescence }\end{array}$ & $\begin{array}{l}\text { shorter than } \\
\text { inflorescence }\end{array}$ & $\begin{array}{l}\text { shorter than } \\
\text { inflorescence }\end{array}$ & $\begin{array}{l}\text { shorter than } \\
\text { inflorescence }\end{array}$ & $\begin{array}{l}\text { shorter than } \\
\text { inflorescence }\end{array}$ \\
\hline C16. Bracteole & absent & absent & absent & absent & absent & absent \\
\hline C17. Bracteole shape & - & - & - & - & - & - \\
\hline C18. Bracteole apex & - & - & - & - & - & - \\
\hline C19. Tepal shape & ovate & lanceolate & lanceolate & lanceolate & lanceolate & lanceolate \\
\hline C20. Tepal apex & obtuse & obtuse & acute & acute & acute & acute \\
\hline C21. Variation of tepals & outer $>$ inner & equal & inner $>$ outer & inner $>$ outer & equal & inner $>$ outer \\
\hline $\begin{array}{l}\text { C22. Length between mature } \\
\text { fruit and tepal }\end{array}$ & tepal $>$ fruit & equal & fruit $>$ tepal & fruit $>$ tepal & fruit $>$ tepal & fruit $>$ tepal \\
\hline C23. Number of stamen & $\operatorname{six}$ & $\operatorname{six}$ & $\operatorname{six}$ & three & three & three \\
\hline C24. Fruit shape & $\begin{array}{l}\text { trigonous } \\
\text { ellipsoid }\end{array}$ & $\begin{array}{l}\text { trigonous } \\
\text { ellipsoid }\end{array}$ & $\begin{array}{l}\text { trigonous } \\
\text { ellipsoid }\end{array}$ & $\begin{array}{l}\text { trigonous } \\
\text { ellipsoid }\end{array}$ & $\begin{array}{l}\text { trigonous } \\
\text { ellipsoid }\end{array}$ & $\begin{array}{l}\text { trigonous } \\
\text { ellipsoid }\end{array}$ \\
\hline $\begin{array}{l}\text { C25. Number of locule(s) in } \\
\text { a fruit }\end{array}$ & $\begin{array}{l}\text { imperfectly } \\
\text { trilocular }\end{array}$ & $\begin{array}{l}\text { imperfectly } \\
\text { trilocular }\end{array}$ & unilocular & unilocular & unilocular & unilocular \\
\hline C26. Seed shape & $\begin{array}{l}\text { narrowly- } \\
\text { ellipsoid }\end{array}$ & $\begin{array}{l}\text { narrowly- } \\
\text { ellipsoid }\end{array}$ & ovoid-ellipsoid & ellipsoid & ellipsoid & ellipsoid \\
\hline C27. Seed appendage & present & present & absent & absent & absent & absent \\
\hline
\end{tabular}


Table 1. Continued.

\begin{tabular}{|c|c|c|c|c|c|c|c|c|}
\hline & J. krameri & J. papillosus & J. bufonius & J. tenuis & J. gracillimus & J. decipiens & J. setchuensis & J. fauriei \\
\hline $\mathrm{C} 1$ & perennial & perennial & annual & perennial & perennial & perennial & perennial & perennial \\
\hline $\mathrm{C} 2$ & no & no & yes & yes & no & no & no & no \\
\hline $\mathrm{C} 3$ & $\begin{array}{l}\text { long- } \\
\text { internoded rhi. }\end{array}$ & stolon & absent & $\begin{array}{l}\text { densely- } \\
\text { internoded rhi. }\end{array}$ & $\begin{array}{l}\text { long- } \\
\text { internoded rhi. }\end{array}$ & $\begin{array}{c}\text { short- } \\
\text { internoded rhi. }\end{array}$ & $\begin{array}{l}\text { short- } \\
\text { internoded rhi. }\end{array}$ & $\begin{array}{l}\text { long- } \\
\text { internoded rhi. }\end{array}$ \\
\hline $\mathrm{C} 4$ & subterete & subterete & terete & terete & terete & terete & terete & flat \\
\hline $\mathrm{C} 5$ & present & present & present & present & present & present & present & present \\
\hline C6 & present & present & present & present & present & absent & absent & absent \\
\hline $\mathrm{C} 7$ & present & present & present & present & present & absent & absent & absent \\
\hline $\mathrm{C} 8$ & obtuse & obtuse & acute & - & acute & - & - & - \\
\hline C9 & present & present & absent & present & present & absent & absent & absent \\
\hline $\mathrm{C} 10$ & obtuse & rounded & - & rounded & obtuse & - & - & - \\
\hline $\mathrm{C} 11$ & perfectly & perfectly & not septate & not septate & not septate & - & - & - \\
\hline $\mathrm{C} 12$ & raceme & raceme & cyme & cyme & cyme & $\begin{array}{l}\text { pseudolateral } \\
\text { cyme }\end{array}$ & $\begin{array}{l}\text { pseudolateral } \\
\text { cyme }\end{array}$ & $\begin{array}{l}\text { pseudolateral } \\
\text { cyme }\end{array}$ \\
\hline $\mathrm{C} 13$ & leaf-like & leaf-like & leaf-like & leaf-like & leaf-like & stem-like & stem-like & stem-like \\
\hline $\mathrm{C} 14$ & obtuse & obtuse & acute & acute & acute & acute & acute & acute \\
\hline $\mathrm{C} 15$ & $\begin{array}{l}\text { shorter than } \\
\text { inflorescence }\end{array}$ & $\begin{array}{l}\text { shorter than } \\
\text { inflorescence }\end{array}$ & $\begin{array}{l}\text { shorter than } \\
\text { inflorescence }\end{array}$ & $\begin{array}{l}\text { longer than } \\
\text { inflorescence }\end{array}$ & $\begin{array}{l}\text { longer than } \\
\text { inflorescence }\end{array}$ & $\begin{array}{l}\text { longer than } \\
\text { inflorescence }\end{array}$ & $\begin{array}{l}\text { longer than } \\
\text { inflorescence }\end{array}$ & $\begin{array}{l}\text { longer than } \\
\text { inflorescence }\end{array}$ \\
\hline $\mathrm{C} 16$ & absent & absent & present & present & present & present & present & present \\
\hline $\mathrm{C} 17$ & - & - & ovate & lanceolate & ovate & lanceolate & ovate & ovate \\
\hline $\mathrm{C} 18$ & - & - & acute & acute & obtuse & acute & acute & acute \\
\hline C19 & lanceolate & lanceolate & lanceolate & lanceolate & ovate & lanceolate & lanceolate & lanceolate \\
\hline $\mathrm{C} 20$ & acute & acute & acute & acute & obtuse & acute & acute & acute \\
\hline $\mathrm{C} 21$ & inner $>$ outer & inner $>$ outer & outer $>$ inner & outer $>$ inner & equal & outer $>$ inner & outer $>$ inner & outer $>$ inner \\
\hline $\mathrm{C} 22$ & fruit $>$ tepal & fruit $>$ tepal & tepal $>$ fruit & tepal $>$ fruit & fruit $>$ tepal & equal & fruit $>$ tepal & fruit $>$ tepal \\
\hline $\mathrm{C} 23$ & six or three & three & $\operatorname{six}$ & $\operatorname{six}$ & $\operatorname{six}$ & three & three & $\operatorname{six}$ \\
\hline $\mathrm{C} 24$ & $\begin{array}{l}\text { trigonous } \\
\text { ellipsoid }\end{array}$ & $\begin{array}{l}\text { trigonous } \\
\text { ellipsoid }\end{array}$ & $\begin{array}{l}\text { trigonous } \\
\text { ellipsoid }\end{array}$ & ovoid & ovoid & $\begin{array}{l}\text { trigonous- } \\
\text { ellipsoid }\end{array}$ & ovoid & ovoid \\
\hline $\mathrm{C} 25$ & unilocular & unilocular & trilocular & $\begin{array}{l}\text { imperfectly } \\
\text { trilocular }\end{array}$ & $\begin{array}{l}\text { imperfectly } \\
\text { trilocular }\end{array}$ & trilocular & $\begin{array}{l}\text { imperfectly } \\
\text { trilocular }\end{array}$ & $\begin{array}{l}\text { imperfectly } \\
\text { trilocular }\end{array}$ \\
\hline $\mathrm{C} 26$ & ellipsoid & ellipsoid & globoid & lunate-obovoid & lunate-obovoid & ellipsoid & lunate- obovoid & ellipsoid \\
\hline $\mathrm{C} 27$ & absent & absent & absent & absent & absent & absent & absent & absent \\
\hline
\end{tabular}

골풀, 별날개골풀, 참비녀골풀, 눈비녀골풀, 애기골풀, 길 골풀이다. 경생엽의 경우 엽신과 만나는 엽초부분에 귀 모 양의 막질인 엽이(auricle)가 둔두(obtuse), 원두(rounded)인 분류군들과 엽이가 없는 분류군이 있다(Fig. $4 \mathrm{D}$, Table 1). 엽이가 둔두인 것은 구름골풀, 실비녀골풀, 날개골풀, 별 날개골풀, 참비녀골풀, 물골풀, 눈비녀골풀, 비녀골풀이 며, 원두인 것은 청비녀골풀, 길골풀(근생엽)이고, 애기골 풀은 엽이가 없다.

화서와 포: Kirschner (2002a, b)는 subg. Agathryon은 취산 화서(cyme)로, subg. Juncus는 총상화서(raceme)로 인식 하 였는데, 한반도의 골풀속 식물들은 이를 반영하고 있다. 취산화서를 형성하는 분류군은 애기골풀, 길골풀, 물골풀, 골풀, 푸른갯골풀, 검정납작골풀이며, 총상화서를 형성하 는 분류군은 구름골풀, 실비녀골풀, 날개골풀, 별날개골 풀, 참비녀골풀, 눈비녀골풀, 비녀골풀, 청비녀골풀이다. 기본 화서형들과 구분되는 변이들로는 구름골풀은 화서 의 절간이 줄어든 두상총상화서(head-type raceme)를 갖고 (Fig. 1A, Table 1), 골풀, 푸른갯골풀, 검정납작골풀은 포가 
A

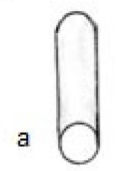

$\square$

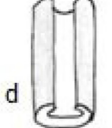

B

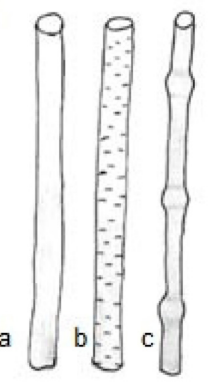

C

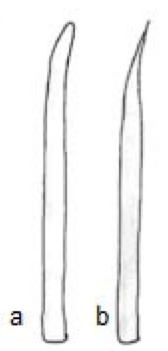

D

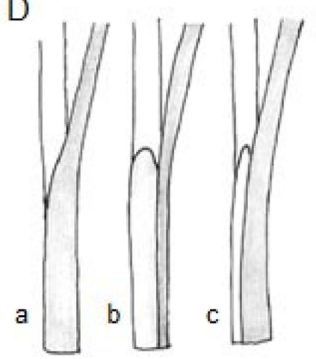

Fig. 4. Leaf characters of the Korean Juncus. A, Shape of cross section (a, terete; b, subterete; c, flat; d, involute); B, Septation (a, not septate; b, imperfectly septate, c, perfectly septate); C, Apex (a, obtuse; b, acute); D, Auricle (a, absent; b, rounded; c, obtuse).
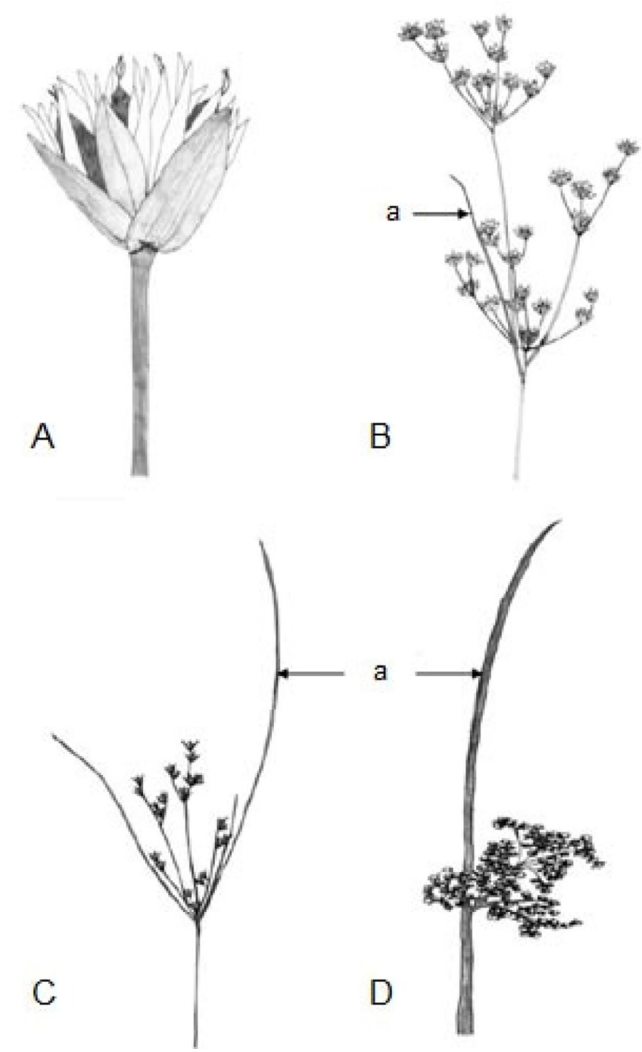

Fig. 5. Inflorescence types of the Korean Juncus. A, Head-type raceme; B, Raceme; C, Cyme; D, Pseudolateral cyme; a, primary bract.
화병과 일직선으로 뻗어 취산화서가 측생하는 것처럼 보 이는 가측생취산화서(pseudolateral cyme)를 갖는다(Fig. 1D, Table 1). 화서 밑의 일차 포의 모양은 잎 유사형(leaflike)과 줄기 유사형(stem-like)이 있다. 일차 포가 잎 유사 형인 분류군은 실비녀골풀, 날개골풀, 별날개골풀, 참비 녀골풀, 비녀골풀, 청비녀골풀, 애기골풀, 길골풀, 물골풀 이며, 줄기 유사형인 분류군은 골풀, 푸른갯골풀, 검정납 작골풀이다. 구름골풀는 유일하게 일차 포가 없다. 일차 포의 길이는 화서보다 짧거나 길며 정단 모양은 둔두이거 나 예두이다. 일차 포의 정단 모양이 둔두인 분류군은 비 녀골풀, 청비녀골풀이며, 예두인 분류군은 날개골풀, 별날 개골풀, 참비녀골풀, 눈비녀골풀, 애기골풀, 길골풀, 물골 풀, 골풀, 푸른갯골풀, 검정납작골풀이다. 실비녀골풀의 경우 화서 기부에 화병이 있으며, 화병 밑에 짧은 잎 같은 포가 있다.

소포: 각 낱꽃의 기부에 화피를 감싸는 1 쌍의 난형 또는 피침형의 막질 소포(bracteole)가 있거나 없다(Fig. 6). 소포의 유무는 Kirschiner의 분류체계(2002a, b)상의 두 아속을 구분 하는 형질이다. 소포가 없는 subg. Juncus에 속하는 분류군 은 구름골풀, 실비녀골풀, 날개골풀, 별날개골풀, 참비녀골 풀, 눈비녀골풀, 비녀골풀, 청비녀골풀이며, 소포를 갖는 subg. Agathryon에 속하는 분류군은 애기골풀, 길골풀, 물골 풀, 골풀, 푸른갯골풀, 검정납작골풀이다. 난상 소포를 갖는 분류군은 애기골풀, 물골풀, 푸른갯골풀, 검정납작골풀이
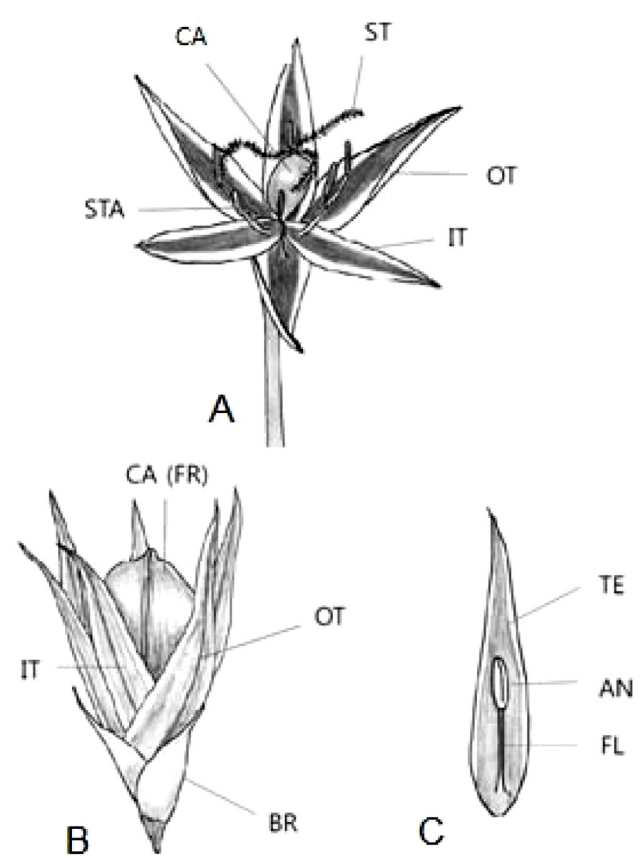

Fig. 6. Flower terminology of the Korean Juncus. A: ST, stigma; CA, carpel; STA, stamen; OT, outer tepal; IT, inner tepal; B: CA, carpel (fruit); IT, inner tepal; OT, outer tepal; BR, bracteole; C: TE, tepal; AN, anther; FL, filament. 
며, 피침형의 소포를 갖는 분류군은 길골풀과 골풀이다.

꽃: 화피는 6 장이 3 개씩 2줄로 배열한다. 대부분 피침형 (lanceolate)의 화피를 이루고 있으나, 구름골풀과 물골풀 의 경우 난형(ovate)의 화피를 이루고 있어서 다른 분류군 들과 뚜렷한 차이를 보인다. 화피의 가장자리는 주로 막 질이다. 화피열편의 정단은 둔두이거나 예두이다. 화피열 편의 정단이 둔두인 분류군은 구름골풀, 실비녀골풀, 물 골풀이며, 예두인 분류군은 날개골풀, 별날개골풀, 참비 녀골풀, 청비녀골풀, 눈비녀골풀, 비녀골풀, 청비녀골풀, 애기골풀, 길골풀, 골풀, 푸른갯골풀, 검정납작골풀이다. 내화피가 외화피보다 긴 분류군은 날개골풀, 별날개골풀, 눈비녀골풀, 비녀골풀 청비녀골풀이며, 내화피와 외화피 의 길이가 비슷한 분류군은 실비녀골풀, 참비녀골풀, 물
골풀이고, 내화피가 외화피보다 짧은 분류군은 구름골풀, 애기골풀, 길골풀, 골풀, 푸른갯골풀, 검정납작골풀이다 (Table 1, 2). 수술의 수는 분류군에 따라3개 또는 6개가 화 피와 대생으로 배열하는데, 수술이 화피보다 긴 분류군은 구름골풀, 실비녀골풀, 청비녀골풀이며, 화피보다 짧은 분 류군은 날개골풀, 별날개골풀, 참비녀골풀, 눈비녀골풀, 비녀골풀, 애기골풀, 길골풀, 물골풀, 골풀, 푸른갯골풀, 검정납작골풀이다(Fig. 6, Table 1, 2). 암술머리는 모든 분 류군에서 3 개로 깊게 갈라진다.

과실: 과실은 3 개의 봉선으로 포배열개하는 삭과 (capsule)인데, 삼릉상 타원형(trigonous ellipsoid)과 난형 (ovoid)으로 구분된다(Fig. 7, Table 1). 과실이 삼릉상 타원형 인 분류군은 구름골풀, 실비녀골풀, 날개골풀, 별날개골풀,

Table 2. Quantitative morphological characters of the Korean Juncus.

\begin{tabular}{|c|c|c|c|c|c|c|}
\hline Taxa & J. triglumis & J. maximowiczii & J. alatus & J. diastrophanthus & $\begin{array}{l}\text { J. prismatocarpus } \\
\text { ssp. leschenaultii }\end{array}$ & J. wallichianus \\
\hline C1. Plant height $(\mathrm{cm})$ & $19(21.1) 23$ & $7.1(11.2) 15.0$ & $31.5(36.7) 41.5$ & $15.3(29.8) 51.0$ & $13.8(21.5) 28.0$ & $22(29.8) 43.8$ \\
\hline C2. Stem height $(\mathrm{cm})$ & $18.2(20.3) 22.2$ & $6.5(10.5) 14.5$ & $26(29.7) 36.1$ & $10.4(21.5) 36.5$ & $9.6(15.4) 20.0$ & $16.1(21.7) 30.8$ \\
\hline C3. Stem diameter $(\mathrm{mm})$ & $0.7(0.9) 1.1$ & $0.2(0.4) 0.6$ & $2.1(2.3) 2.5$ & $1.3(1.7) 2.4$ & $0.9(1.3) 1.8$ & $1.0(1.1) 1.6$ \\
\hline C4. Internode length $(\mathrm{cm})$ & $2.0(2.6) 3.5$ & $0.0(2.6) 5.3$ & $7.5(8.4) 10.4$ & $2.7(6.9) 15.3$ & $3.3(5.3) 8.2$ & $5.0(8.0) 12.3$ \\
\hline C5. Basal leaf number (no.) & $1.0(1.8) 2.0$ & $1.0(1.8) 3.0$ & $0.0(0.8) 1.0$ & $0.0(1.2) 2.0$ & $0.0(0.5) 1.0$ & $0.0(0.3) 1.0$ \\
\hline C6. Basal leaf legth (cm) & $5.0(6.3) 7.0$ & $6.2(10.2) 15.4$ & $0.0(8.5) 16.1$ & $1.9(14.0) 83$ & $0.0(5.2) 13.6$ & $0.0(4.2) 4.8$ \\
\hline C7. Cauline leaf number (no.) & $2.0(2.0) 2.0$ & $1.0(1.8) 2.0$ & $3.0(3.8) 5.0$ & $2.0(3.1) 4.0$ & $2.0(2.9) 3.0$ & $2.0(2.8) 3.0$ \\
\hline C8. Cauline leaf legth $(\mathrm{cm})$ & $4.0(9.7) 12$ & $6.3(6.9) 7.3$ & $10.0(13.3) 18.4$ & $6.1(11.2) 19.9$ & $3.4(7.2) 10.3$ & $1.9(9.8) 11.8$ \\
\hline C9. Cauline leaf width (mm) & $0.5(0.8) 1.0$ & $0.7(0.9) 1.1$ & $2.6(3.3) 3.6$ & $1.4(2.6) 4.3$ & $0.9(1.7) 2.5$ & $1.0(1.5) 1.8$ \\
\hline C10. Leaf sheath number (no.) & $2.0(2.0) 2.0$ & $1.0(1.8) 2.0$ & $3.0(3.8) 5.0$ & $2.0(3.1) 4.0$ & $2.0(2.9) 3.0$ & $2.0(2.8) 3.0$ \\
\hline C11. Leaf sheath length $(\mathrm{cm})$ & $2.0(2.8) 3.8$ & $0.7(1.2) 1.6$ & $3.0(3.1) 3.2$ & $1.7(3.2) 5.7$ & $0.9(2.4) 2.8$ & $1.8(3.0) 4.4$ \\
\hline C12. Cataphyll number (no.) & 0.0 & $1.0(1.3) 2.0$ & $0.0(0.3) 1.0$ & $0.0(1.1) 2.0$ & $0.0(0.2) 1.0$ & $1.0(1.0) 1.0$ \\
\hline C13. Cataphyll length $(\mathrm{cm})$ & 0.0 & $0.4(0.8) 1.0$ & $0.0(0.6) 2.4$ & $0.0(1.7) 2.9$ & $0.0(0.5) 2.8$ & $0.0(1.8) 2.3$ \\
\hline C14. Inflorescence length $(\mathrm{cm})$ & $0.7(0.8) 0.8$ & $0.5(0.6) 0.7$ & $2.3(6.4) 12.0$ & $2.7(8.6) 14.4$ & $3.6(6.0) 10.1$ & $3.7(6.8) 12.1$ \\
\hline C15. Inflorescence width $(\mathrm{cm})$ & $0.7(0.8) 0.9$ & $0.4(0.5) 0.6$ & $1.5(4.2) 11$ & $2.1(6.5) 11.9$ & $1.7(4.2) 7.8$ & $2.2(4.5) 10.3$ \\
\hline C16. Lower bract length $(\mathrm{cm})$ & 0.0 & 0.0 & $2.3(3.4) 5.0$ & $1.1(3.9) 6.9$ & $1.0(2.8) 3.9$ & $1.8(3.6) 8.7$ \\
\hline C17. Lower bract width (mm) & 0.0 & 0.0 & $0.5(1.4) 2.5$ & $0.4(1.3) 2.6$ & $0.3(1.1) 1.8$ & $0.5(0.9) 1.7$ \\
\hline C18. Bracteole number (no.) & 0.0 & 0.0 & 0.0 & 0.0 & 0.0 & 0.0 \\
\hline C19. Bracteole length (mm) & 0.0 & 0.0 & 0.0 & 0.0 & 0.0 & 0.0 \\
\hline C20. Bracteole width (mm) & 0.0 & 0.0 & 0.0 & 0.0 & 0.0 & 0.0 \\
\hline C21. Tepal legth (mm) & $4.4(5.0) 5.5$ & $3.1(3.3) 3.6$ & $3.3(3.4) 3.7$ & $3.0(3.5) 4.1$ & $3.2(3.4) 3.9$ & $2.1(3.0) 3.3$ \\
\hline C22. Tepal width (mm) & $1(1.2) 1.5$ & $0.8(0.9) 1.0$ & $0.9(1.0) 1.1$ & $0.5(0.6) 0.8$ & $0.3(0.6) 0.7$ & $0.5(0.6) 0.8$ \\
\hline C23. Stamen number (no.) & $6.0(6.0) 6.0$ & $6.0(6.0) 6.0$ & $6.0(6.0) 6.0$ & $3.0(3.0) 3.0$ & $3.0(3.0) 3.0$ & $3.0(3.0) 3.0$ \\
\hline C24. Capsule length (mm) & $3.8(4.1) 4.3$ & $3.5(4.1) 5.0$ & $3.5(3.8) 4.0$ & $3.7(4.7) 5.5$ & $3.5(3.9) 4.4$ & $3.1(4.0) 4.5$ \\
\hline C25. Capsule width (mm) & $1.5(1.6) 1.7$ & $1.6(2.4) 3.0$ & $1.2(1.4) 1.6$ & $0.9(1.1) 1.4$ & $1.0(1.2) 1.4$ & $0.9(1.1) 1.5$ \\
\hline C26. Seed length $(\mathrm{mm})$ & $1.2(1.4) 1.7$ & $1.2(1.4) 1.5$ & $0.4(0.4) 0.5$ & $0.5(0.5) 0.6$ & $0.5(0.5) 0.6$ & $0.5(0.5) 0.6$ \\
\hline C27. Seed width (mm) & $0.1(0.2) 0.2$ & $0.1(0.2) 0.3$ & $0.2(0.2) 0.2$ & $0.2(0.2) 0.3$ & $0.2(0.2) 0.2$ & $0.2(0.2) 0.2$ \\
\hline
\end{tabular}


Table 2. Continued.

\begin{tabular}{|c|c|c|c|c|c|c|c|c|}
\hline & J. krameri & J. papillosus & J. bufonius & J. tenuis & J. gracillimus & J. decipiens & J. setchuensis & J. fauriei \\
\hline $\mathrm{C} 1$ & 17 (42.7) 55.0 & $15.0(34.3) 70.0$ & 9.2 (14.8) 23.5 & $19.5(38.8) 82.5$ & 33.5 (58.2) 95.0 & 7.8 (67.9) 130.0 & $35.0(62.3) 90.0$ & $40.0(52.5) 60.0$ \\
\hline $\mathrm{C} 2$ & $10.0(32.8) 42.0$ & $7.6(23.4) 46.5$ & $4.4(7.8) 11.5$ & $12.0(30.3) 73$ & $34.0(48.8) 75$ & $21.0(56.6) 112.0$ & $023.0(46.9) 74.0$ & $26.0(36.8) 50.0$ \\
\hline $\mathrm{C} 3$ & $1.0(1.4) 1.8$ & $0.7(1.2) 1.8$ & $0.4(0.6) 0.9$ & $0.5(0.8) 1.5$ & $0.6(0.9) 1.4$ & $1.0(1.5) 1.9$ & $0.9(1.2) 1.6$ & $0.9(1.4) 1.7$ \\
\hline $\mathrm{C} 4$ & $5.9(11.3) 16.5$ & $3.1(7.7) 11.5$ & $0.0(2.7) 5.1$ & $1.0(1.8) 4.4$ & $5.9(15.3) 29$ & 0.0 & 0.0 & $0.9(1.2) 1.5$ \\
\hline $\mathrm{C} 5$ & $0.0(1.0) 1.0$ & $1.0(1.1) 2.0$ & $0.0(1.0) 1.0$ & $1.0(1.9) 2.0$ & $2.0(2.5) 4.0$ & 0.0 & 0.0 & 0.0 \\
\hline $\mathrm{C} 6$ & $0.0(8.1) 15.5$ & $2.6(6.7) 13.1$ & $0.0(2.9) 4.8$ & 8.9 (14.8) 19.7 & $15.0(27.7) 39$ & 0.0 & 0.0 & 0.0 \\
\hline $\mathrm{C} 7$ & $2.0(2.8) 3.0$ & $2.0(3.0) 4.0$ & 1.0 (1.6) 2.0 & 0.0 & $1.0(1.9) 3.0$ & 0.0 & 0.0 & 0.0 \\
\hline $\mathrm{C} 8$ & $1.1(19.5) 28.0$ & 1.7 (13.4) 25.0 & $0.3(0.7) 1.0$ & 0.0 & $1.3(2.3) 3.5$ & 0.0 & 0.0 & 0.0 \\
\hline C9 & $1.0(1.7) 2.3$ & $0.7(1.6) 2.5$ & $0.4(0.6) 0.8$ & 0.0 & $0.7(0.9) 1.4$ & 0.0 & 0.0 & 0.0 \\
\hline $\mathrm{C} 10$ & $2.0(2.8) 3.0$ & $2.0(3.0) 4.0$ & 1.0 (1.6) 2.0 & 0.0 & $3.0(4.3) 6.0$ & 0.0 & 0.0 & 0.0 \\
\hline $\mathrm{C} 11$ & $2.3(4.2) 6.0$ & $2.0(2.9) 5.9$ & $0.6(1.2) 1.5$ & 0.0 & $2.0(7.8) 12.4$ & 0.0 & 0.0 & 0.0 \\
\hline $\mathrm{C} 12$ & 0.0 & $0.0(0.1) 0.1$ & $0.0(1.0) 1.0$ & $0.0(0.2) 1.0$ & $0.0(0.4) 1.0$ & $2.0(2.9) 4.0$ & $2.0(2.5) 3.0$ & $2.0(3.0) 4.0$ \\
\hline $\mathrm{C} 13$ & 0.0 & $0.0(0.2) 2.8$ & $0.0(1.3) 2.1$ & $0.0(0.4) 2.5$ & $0.0(1.1) 3.5$ & 4.2 (11.1) 20.1 & $5.0(8.9) 13.6$ & $7.1(8.2) 8.6$ \\
\hline $\mathrm{C} 14$ & $4.9(10.0) 14.5$ & 3.7 (10.4) 22.5 & $2.9(6.7) 15.3$ & 2.0 (4.4) 9.2 & $2.4(5.4) 7.8$ & $1.5(2.9) 4.1$ & $1.8(3.8) 6.5$ & $3.7(4.1) 4.5$ \\
\hline $\mathrm{C} 15$ & $2.0(5.2) 10.6$ & $2.1(6.9) 15.4$ & $0.9(2.5) 7.0$ & $1.0(2.4) 7.7$ & $1.1(2.1) 4.0$ & $1.0(2.7) 3.8$ & 0.9 (2.6) 5.5 & $1.7(2.0) 2.3$ \\
\hline $\mathrm{C} 16$ & $2.0(5.7) 10.8$ & $1.6(3.5) 5.8$ & $2.1(4.3) 8.5$ & $4.5(8.7) 15.3$ & $4.8(8.3) 18.5$ & $7.1(14.2) 25.5$ & $7.0(15.3) 29.0$ & $6.0(9.7) 13.0$ \\
\hline $\mathrm{C} 17$ & $0.7(1.0) 1.6$ & $0.3(0.8) 2.0$ & $0.2(0.5) 0.7$ & $0.4(0.7) 1.0$ & $0.3(0.6) 0.8$ & $0.8(3.0) 2.5$ & $0.7(1.0) 1.4$ & $1.0(1.2) 1.3$ \\
\hline $\mathrm{C} 18$ & 0.0 & 0.0 & $2.0(2.0) 2.0$ & $2.0(2.0) 2.0$ & $2.0(2.0) 2.0$ & $2.0(2.0) 2.0$ & $2.0(2.0) 2.0$ & $2.0(2.0) 2.0$ \\
\hline C19 & 0.0 & 0.0 & $1.6(2.4) 3.4$ & $1.5(1.8) 2.3$ & $0.9(1.3) 1.7$ & $1.0(1.2) 1.5$ & $0.9(1.3) 1.6$ & $1.8(1.9) 1.9$ \\
\hline $\mathrm{C} 20$ & 0.0 & 0.0 & $1.0(1.5) 2.0$ & $0.9(1.2) 1.5$ & $0.7(0.9) 1.5$ & $0.6(0.8) 1.1$ & $0.6(1.0) 1.4$ & $1.4(1.5) 1.5$ \\
\hline $\mathrm{C} 21$ & $2.3(2.9) 3.7$ & $2.0(2.2) 2.6$ & $5.2(5.5) 6.3$ & 3.5 (4.1) 4.6 & $1.6(2.1) 2.5$ & $2.1(2.4) 2.6$ & 2.0 (2.6) 3.0 & $2.9(3.1) 3.4$ \\
\hline $\mathrm{C} 22$ & $0.6(0.7) 0.8$ & $0.4(0.6) 0.7$ & $0.8(1.1) 1.4$ & $0.9(1.0) 1.3$ & $0.6(0.7) 0.9$ & $0.5(0.6) 1.0$ & $0.8(0.9) 1.2$ & $0.9(1.2) 1.5$ \\
\hline $\mathrm{C} 23$ & $3.0(3.0) 3.0$ & $3.0(3.0) 3.0$ & $6.0(6.0) 6.0$ & $6.0(6.0) 6.0$ & $6.0(6.0) 6.0$ & $3.0(3.0) 3.0$ & $3.0(3.0) 3.0$ & $6.0(6.0) 6.0$ \\
\hline $\mathrm{C} 24$ & $2.3(3.1) 3.8$ & $2.6(3.6) 4.5$ & $2.0(3.7) 4.5$ & $2.1(2.9) 3.4$ & $1.3(2.0) 2.7$ & $2.3(2.5) 2.7$ & 1.9 (2.6) 3.1 & $3.0(3.5) 4.0$ \\
\hline $\mathrm{C} 25$ & $0.8(1.0) 1.2$ & $0.6(0.9) 1.1$ & $0.8(1.5) 2.7$ & $1.3(1.8) 2.4$ & $1.2(1.3) 2.2$ & $1.1(1.4) 1.8$ & $1.0(1.7) 2.0$ & $1.8(1.9) 2.0$ \\
\hline $\mathrm{C} 26$ & $0.5(0.5) 0.6$ & $0.5(0.5) 0.6$ & $0.3(0.5) 0.6$ & $0.3(0.46) 0.5$ & $0.3(0.4) 0.5$ & $0.5(0.5) 0.6$ & $0.4(0.5) 0.6$ & $0.7(0.8) 0.9$ \\
\hline $\mathrm{C} 27$ & $0.2(0.2) 0.2$ & $0.2(0.2) 0.2$ & $0.2(0.2) 0.3$ & $0.1(0.19) 0.2$ & $0.1(0.17) 0.2$ & $0.2(0.2) 0.3$ & $0.2(0.2) 0.2$ & $0.4(0.5) 0.5$ \\
\hline
\end{tabular}

* minimum (mean) maximum

참비녀골풀, 눈비녀골풀, 비녀골풀, 청비녀골풀, 애기골풀, 골풀이며, 난형인 분류군은 길골풀, 물골풀, 푸른갯골풀, 검정납작골풀이다. 과실의 방(locule)은 1 실형(unilocular), 3 실형(trilocular), 불완전 3실형 $=3$ 격막형; imperfectly trilocular)으로 구분된다. 과실의 방이 1실인 분류군은 날개골풀, 별날개골풀, 참비녀골풀, 눈비녀골풀, 비녀골풀, 청비녀골 풀이며, 불완전 3 실인 분류군은 구름골풀, 실비녀골풀, 길 골풀, 물비녀골풀, 푸른갯골풀, 검정납작골풀이고, 3 실을 갖는 분류군은 애기골풀과 골풀이다.

종자: 종자는 꼬리모양의 부속체를 갖는(appendaged) 좁 은 타원체형(narrowly ellipsoid), 타원형 (ellipsoid), 난상타원 형(ovoid-ellipsoid), 초승달 모양의 도란형(lunate obovoid), 구형(globoid)으로 분류된다(Fig. 8, Table 1). 부속체가 달려
있는 좁은 타원형의 종자를 갖는 분류군은 구름골풀과 실 비녀골풀이며, 타원형을 갖는 분류군은 별날개골풀, 참비 녀골풀, 눈비녀골풀, 비녀골풀, 청비녀골풀, 골풀, 검정납 작골풀이고, 난상 타원체를 갖는 분류군은 날개골풀이고, 초승달 모양의 도란형은 길골풀, 물골풀, 푸른갯골풀이고, 구형을 갖는 분류군은 애기골풀이다. 종자의 표피세포는 사각형 또는 다각형의 세포로 이루어지는데, 두꺼운 망상 맥을 형성하는 세포벽 사이는 결절이 발달되고, 망상무늬 안쪽에 다시 세포벽이 얇은 맥을 형성한다(Fig. 9). 골풀속 식물의 종자 표피구조는 속내 절 또는 종간의 분류 형질로 사용된 바 있는데(Satake, 1932; Brooks \& Kuhn, 1986; Kardrym \& Khalik, 2010), 본 논문에서는 한국산 골풀속 식 물의 종자에 대해서 부속체의 존재, 종자의 형태만을 분류 


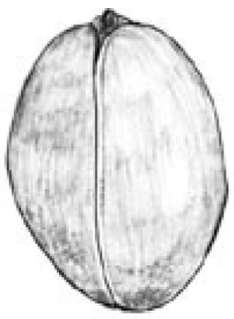

A

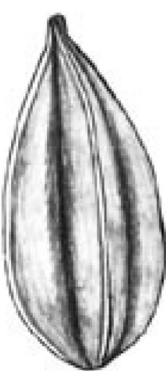

B

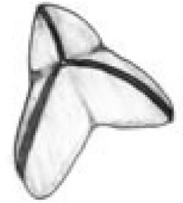

C

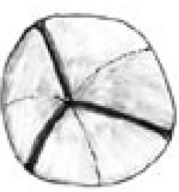

$\mathrm{D}$

Fig. 7. Fruit types of the Korean Juncus. A and B, ovoid; C and D, trigonous oblong. A and $\mathrm{C}$, horizontal view; $\mathrm{B}$ and $\mathrm{D}$, top view.

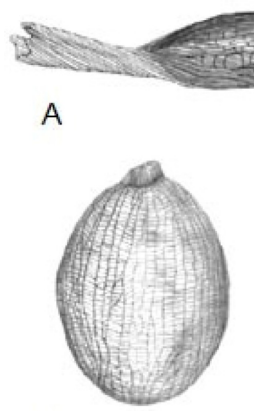

B

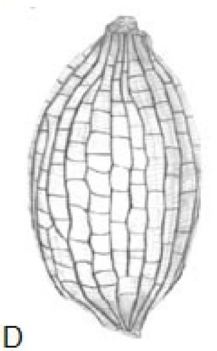

C

E
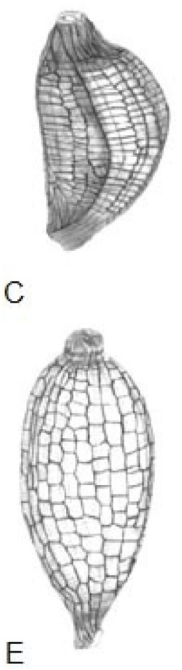

Fig. 8. Seed types of the Korean Juncus. A, Narrowly ellipsoid; B, Globoid; C, Lunate obovoid; D, Ovoid ellipsoid; E. Ellipsoid.

군들을 구분 할 수 있는 형질로 사용하였고, 표피무늬에 대한 자세한 형질들의 이용을 위해서는 향후 추가적인 연 구를 통해 분류군내 변이 파악이 선행되어야 할 것으로 생각된다.

질적 형질들의 유형 구분과 양적 형질들의 측정값들은 Table 1과 Table 2에 종합하였고, 이들을 바탕으로 한반도에 분포하는 골풀속 분류군들에 대한 검색표를 작성하였다.

\section{한국산 골풀속 분류군 검색표}

1. 화서는 총상화서이고, 꽃에 한 쌍의 소포가 없으며, 여러 개의 꽃이 밀집화를 이룬다[Subg. Juncus]

2. 화서는 1 개의 두상화를 이루며, 종자에 꼬리모양의 부속체가 있다[sect. Stygiopsis]

3. 화피는 담갈색이고, 화서 기부에 화병이 없다

구름골풀J. triglumis

3. 화피는 흰색이고, 화서 기부에 화병이 있으며 화 병 밑에 잎 같은 작은 포가 있다

실비녀골풀J. maximowiczii

2. 화서는 여러 개의 두상화를 이루고, 종자에 꼬리모 양의 부속체가 없다.

4. 잎은 납작하며 다관질이며 불완전한 격막을 갖 고 줄기에 날개가 있다[sect. Iridifolli]

5. 수술은 6 개이고 줄기에 넓은 날개가 있다

날개골풀J. alatus

5. 수술은 3 개이고 줄기에 좁은 날개가 있다.

6. 두상화는 구형이고, 열매 길이는 화피보다 매우 길다....... 별날개골풀J. diastrophanthus

6. 두상화는 반구형이고, 열매 길이는 화피와 비슷하다

............... 참비녀골풀J. prismatocarpus subsp. leschenaultii

4. 잎은 원형이거나 타원형이며 단관질이고 완전한 격막을 가지며, 줄기에 날개가 없다[sect. Ozophyllum]

7. 잎은 원형이며, 지하경은 밀집절간형이다 눈비녀골풀J. wallichianus

7. 잎은 타원형이며, 지하경은 장절간형 또는 포 복지형이다.

8. 지하경은 장절간형이며, 두상화는 4-10개의 꽃으로 되어 있고, 삭과의 길이는 $(2.3-3.8 \mathrm{~mm})$ 화피 $(2.0-3.6 \mathrm{~mm})$ 와 비슷하다

비녀골풀J. krameri

8. 지하경은 포복지형이며, 두상화는 2-3개의 꽃으로 되어 있고, 삭과의 길이는(2.6-4.5 $\mathrm{mm})$ 화피 $(2.0-2.6 \mathrm{~mm})$ 보다 길다

청비녀골풀J. papillosus

1. 화서는 취산화서이고, 꽃에 한 쌍의 소포가 있으며, 꽃은 단독으로 핀다[Subg. Agathryon]

9. 일년생이고, 식물체의 높이는 $9-20 \mathrm{~cm}$ 이며, 내/외화 피의 모양과 길이가 뚜렷이 다르고, 삭과는 3 실이 며, 종자는 구형이다[sect. Tenageia]

애기골풀J. bufonius

9. 다년생이고, 식물체의 높이는 $20 \mathrm{~cm}$ 이상이며, 내/ 외화피의 모양은 같고, 삭과는 불완전 3실이며, 종 자는 구형이 아니다. 
10. 화서가 정생하고, 일차 포는 줄기의 연장처럼 보 이지 않고 잎모양이다[sect. Steirochloa]

11. 지하경은 밀집절간형이고, 화피는 피침형이며 예두이고 길이는 3.5-4.6 mm로 삭과(길이 2.1$3.4 \mathrm{~mm}$ )보다 길다 ......................... 길골풀J. tenuis

11. 지하경은 장절간형이고, 화피는 난형이며 둔두
이고 길이는 $1.6-2.5 \mathrm{~mm}$ 로 삭과(길이 $1.3-2.7 \mathrm{~mm}$ ) 와 비슷하다............................ 물골풀J. gracillimus

10. 화서가 가측생하고, 일차 포는 줄기의 연장처럼 보이고 줄기 모양이다[sect. Juncotypus]

12. 화피의 가장자리가 넓고 검정색이며, 수술은 6 개이고, 줄기는 편평형이며 주로 나선상으로
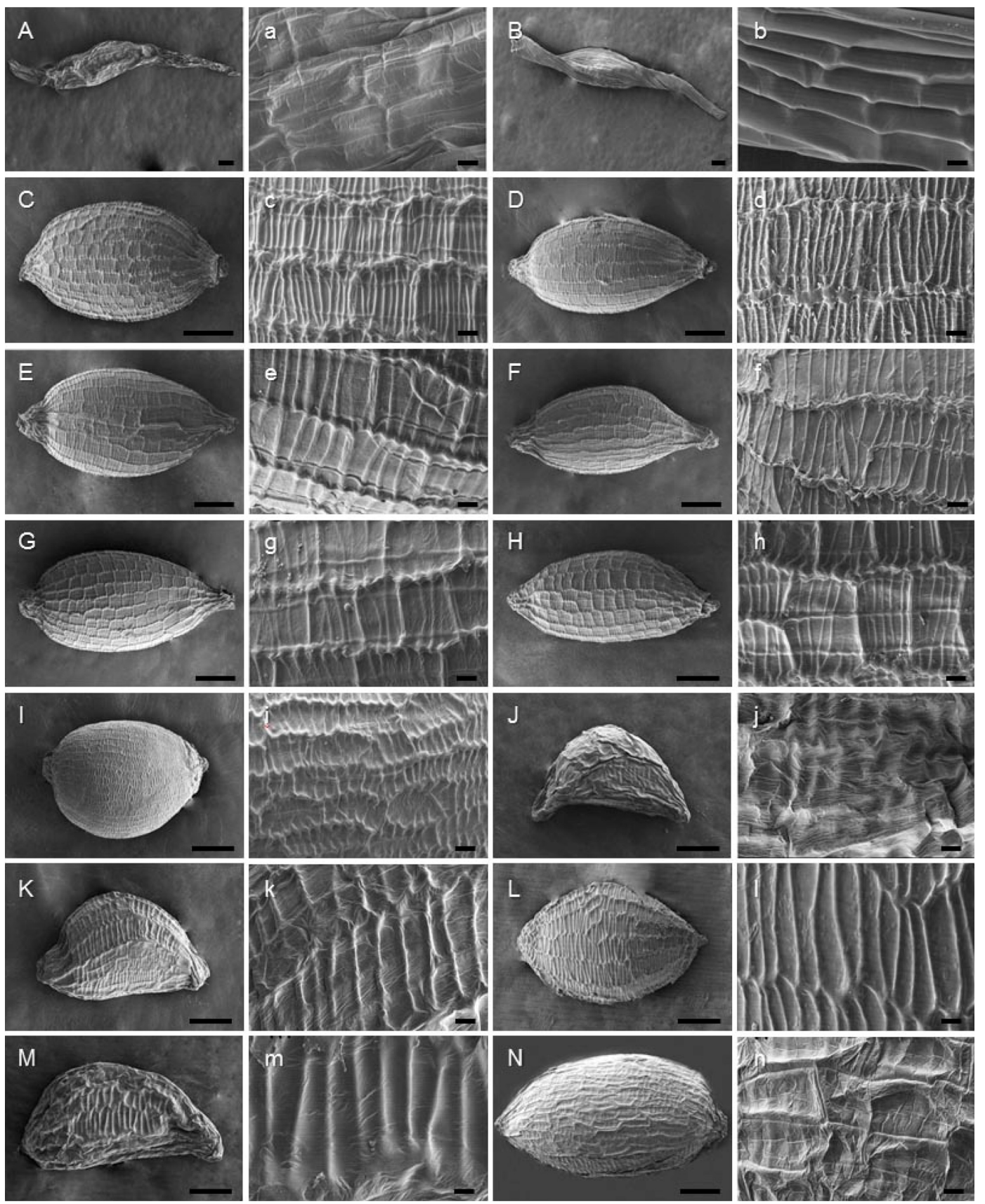

Fig. 9. SEM images of seeds and magnified surfaces of the Korean Juncus. A and a, J. triglumis; B and b, J. maximowiczii; C and c, J. alatus; $\mathrm{D}$ and $\mathrm{d}, J$. diastrophanthus; $\mathrm{E}$ and e, J. prismatocarpus subsp. leschenaultii; $\mathrm{F}$ and $\mathrm{f}, J$. wallichianus; $\mathrm{G}$ and g, J. krameri; $\mathrm{H}$ and h, J. papillosus; I and i, J. bufonius; J and j, J. tenuis; K and k, J. gracillimus; L and 1, J. decipiens: $\mathrm{M}$ and $\mathrm{m}$, J. setchuensis; N and n, J. fauriei. Scale bars of A-N are 100um and a-n are $10 \mathrm{um}$, respectively. 
꼬인다 검정납작골풀 $J$ fauriei

12. 화피의 가장자리가 좁고 갈색이며, 수술은 3 개 이고, 줄기는 원통형이며 일직선이다.

13. 줄기에 세로줄이 뚜렷하지 않고, 삭과는 길이 가 화피와 비슷하며 3실이다.... 골풀J. decipiens

13. 줄기에 세로줄이 뚜렷하며, 삭과는 길이가 화 피 보다 길고 불완전한 3실이다

푸른갯골풀J. setchuensis

골풀과에 대한 최근 분자계통학적 연구에서 골풀속은 꿩의밥속, Oxychloë, Distichia와 함께 하나의 분계조를 이 루고 있어 골풀속이 병계통군(paraphyletic group)임을 보 여주고 있고(Drábková et al., 2003; Roalson, 2005), 또한 골 풀속 내의 subg. Juncus와 subg. Agathryon과 같은 주요 아 속들도 병계통군임이 밝혀졌다. 그러므로 지금까지 형태 적인 연구에 의해 확립된 골풀속내의 분류체계(예를 들면 Kirschner, 2002a, b)에 대한 재검토가 요구되고 있지만 현 재까지는 새로운 분류체계 확립을 위한 충분한 분자계통 학적인 자료가 축적되지 못한 상태이다. 앞으로 다수의 유전자구간으로부터 수집된 충분한 분자계통학적 자료 와 기존의 형태적 형질들의 통합적 고찰에 의해 골풀속의 속에 대한 한계 제시와 함께 명확한 속내 분류체계를 확 립할 수 있을 것이다. 향후 이러한 연구와 병행한 한반도 에 분포하는 골풀속 식물들에 대한 분자계통학적연구는 이들에 대한 명확한 속내의 계통학적 위치를 제시할 수 있고, 이를 통해 한반도에 분포하는 골풀속 분류군들의 외부형태학적 형질에 대한 진화적 고찰이 가능할 것이다.

\section{사 사}

이 논문은 2011년도 성신여자대학교 학술연구조성비 지원에 의하여 연구되었음을 밝힙니다.

\section{인용문헌}

Balslev, H. 1996. Flora Neotropica: Juncaceae. The New York Botanical Garden. New York.

Brooks, R. E. and C. Kuhn. 1986. Seed morphological under SEM and microscopy in Kansas Juncus (Juncaceae). Brittonia 38: 201-209.

Buchenau, F. 1890. Monographia Juncacearum in Engler. Botanische Jahrbücher für Systematik. 12: 1-495.

Chung, T. H. 1957. Korean Flora. Kyo-yuk publishing Co. Seoul. (in Korean)

Chung, T. H., P. S. To, B. D. Lee and F. J. Lee. 1937. Nomina Plantarum Koreanum. Chosen National History Institute. Seoul. (in Korean).

Clemants, E. 1990. Juncaceae of New York State. New York State
Museum. New York.

Cronquist, A. 1981. An Intergrated System of Classification of Flowering Plants. Columbia University Press. New York.

Drew Yor, L., J. Kirschner, O. Seberg, G. Petersen, and , aVlG. . 2003. Phylogeny of the Juncaceae based on $r b c L$ sequences, with special emphasis on Luzula DC. and Juncus L. Plant Systematics and Evolution 240: 133-147.

Im, R. J. 2000. Flora Coreana vol. 8. The Science and Technology publishing house. Pyongyang. (in Korean)

Jussieu, A. L. de 1789. Genera Plantarum. Et Theophilum Barrois, Paris.

Kardrym, N. and A. Khalik. 2010. Seed coat morphology and its systematic significance in Juncus L. (Juncaceae) in Egypt. Journal of Systematic Evolution 48: 215-223.

Korea National Arboretum and the Plant Taxonomic Society of Korea. 2007. A Synonymic List of Vascular Plants in Korea. Korea National Arboretum, Pocheon. Pp. 338-339. (in Korean)

Kim, S. M. 2012 Phylogeny and classification of Juncus: focused on Korean taxa. Ph.D. dissertation. Sungshin Women's University. Seoul. (in Korean)

Kim et al., 2012. Juncus fauriei Lév. \& Vaniot (Juncaceae): A new record in Korea. Korean Journal of Plant Taxonomy 42: 330334. (in Korean)

Kirschner, J. 2002a. Juncaceae 2: Juncus subg. Juncus, Species Plantarum: Flora of the World Part 7. Australian Biological Resources Study. Canberra.

Kirschner, J. 2002b. Juncaceae 3: Juncus subg. Agathryon, Species Plantarum: Flora of the World Part 8 Australian Biological Resources Study. Canberra.

Lee, T. B. 1989. Illustrated Flora of Korea. Hyang-mun publishing Co. Seoul. (in Korean)

Lee, W. T. 1996a. Colored Standard Illustrations of Korean Plants. Academy publishing Co. Seoul. (in Korean)

Lee, W. T. 1996b. Lineamenta Florae Koreae. Academy publishing Co. Seoul. (in Korean)

Lee, Y. N 1996. Flora of Korea. Kyo-hak Publishing Co. Seoul. (in Korean)

Linnaeus, C. 1753. Species Plantarum. Impensis Laurentii Salvii. Holmiae.

Mabberley, D. 1987. The Plant-Book. Cambridge University Press. Cambridge.

Munro, S. L. and H. P. Linder. 1998. The phylogenetic position of Prionium (Juncaceae) within the order Juncales based on morphological and $r b c L$ sequence data. Systematic Botany 23: 4355.

Nakai, T. 1911. Flora Koreana II. The Journal of the College of Science, Imperial University of Tokyo. 31: 266-268. 
Nakai, T. 1952. A Synoptical Sketch of Korea Flora. Tokyo Natural Science and Museum. Tokyo.

Novara, L. J. 1976. Contribution al conocimiento de las inflorescencias de Juncus y su signification taxonomica. Kurtziana 9: 41-61.

Oh, Y. C. and Lee. C. S. 2007. Juncaceae In The Genera of Vascular Plants of Korea, Park, C.-W. (ed.), Academy Publishing Co. Seoul. (in Korean)

Palibin, J. 1901. Conspectus Florae Koreae III. Acta Horti Petropoli 19: 16-17.

Park, M. K. 1949. An Enumeration of Korean Plants. Ministry of education. Seoul. (in Korean)

Roalson, H. 2005. Phylogenetic relationship in the Juncaceae inferred from nuclear ribosomal DNA internal transcribed spacer sequence data. International Journal of Plant Sciences 166: 397-413.

Satake, Y. 1931a. Systematic and anatomical studies on the Japanese Juncaceae (1). Botanical Magazine (Tokyo) 45: 235-249.

Satake, Y. 1931b. Systematic and anatomical studies on the Japanese Juncaceae (2). Botanical Magazine (Tokyo) 45: 446-453.

Satake, Y. 1932. Systematic and anatomical studies on the Japanese Juncaceae (3). Botanical Magazine (Tokyo) 46: 639-658.

Satake, Y. 1938. Nova Flora Japonica I Juncaceae. The Sanseido Co., Ltd., Tokyo \& Osaka.

Takhtajan, A. 1997. Diversity and Classification of Flowering Plants. Columbia University Press, New York. 